\title{
Biochar as a Cadmium Scavenger in the Aquatic Environment Remediation: Date Seeds as Raw Material
}

\author{
Amjad Al-Tarawneh ${ }^{1}$ \\ 1 Prince Faisal Center for Dead Sea, Environmental and Energy Research, Mutah University, Karak, 61710, Jordan \\ e-mail: amjtar@mutah.edu.jo
}

\begin{abstract}
It was found that date seeds are suitable for biochar production due to their low moisture content $8.92 \%$, low ash yield $1.05 \%$, and high organic matter content $78.3 \%$. The biochar was produced by pyrolysis at 350,450 and $550^{\circ} \mathrm{C}$. The effect of pyrolysis temperature on the physicochemical characteristics of biochar was investigated. It was found that the porosity, water holding capacity, ash content, $\mathrm{pH}$, organic matter, fixed carbon, and the elemental content of $\mathrm{Na}, \mathrm{K}, \mathrm{Ca}, \mathrm{Mg}, \mathrm{Fe}, \mathrm{Mn}, \mathrm{P}, \mathrm{Zn}, \mathrm{Ba}, \mathrm{Cr}, \mathrm{Cu}, \mathrm{Ni}, \mathrm{Pb}, \mathrm{Ti}$, and $\mathrm{V}$ were increased along with pyrolysis temperature. Meanwhile, the biochar yield, bulk density, and the total content of $\mathrm{N}$ and $\mathrm{S}$ were decreased. The biochar was tested as a sustainable adsorbent to investigate the adsorption of Cd from contaminated water. The adsorption isotherms of $\mathrm{Cd}$ on biochar were determined based on Langmuir equation. The maximum adsorption of $\mathrm{Cd}$ at $25^{\circ} \mathrm{C}$ and $\mathrm{pH} 7$ were 667,714 , and $833 \mathrm{mg} / \mathrm{kg}$ for the biochars produced at 350,450 , and $550^{\circ} \mathrm{C}$, respectively. On the basis of the physicochemical characteristics of the biochar and the findings from Langmuir equation that showed the biochar produced at $550^{\circ} \mathrm{C}$ has the highest adsorption capacity for $\mathrm{Cd}$, the desorption/ adsorption experiment was carried out using the biochar produced at $550^{\circ} \mathrm{C}$. The adsorption of $\mathrm{Cd}$ by biochar was directly proportional to the $\mathrm{Cd}$ concentrations. It was increased from $0.009 \mathrm{mmol} / 0.5 \mathrm{~g}$ at $0.01 \mathrm{mmol} \mathrm{Cd}$ to 0.12 $\mathrm{mmol} / 0.5 \mathrm{~g}$ at $0.2 \mathrm{mmol} \mathrm{Cd}$ concentration. The desorption of $\mathrm{Cd}$ from biochar was increased proportionally to cadmium concentrations from 0.01 to $0.05 \mathrm{mmol}$ and became constant above $0.05 \mathrm{mmol}$, regardless of the increment of cadmium concentrations. High retention potential for the cadmium that adsorbed within the biochar was proven in this study with desorption/adsorption percentage of $16 \%$. These findings provide a successful example of date seeds converting into the sustainable adsorbent for $\mathrm{Cd}$ removal from aquatic environment to achieve the conception of eco-friendly production, which should be studied further.
\end{abstract}

Keywords: biochar, date seeds, pyrolysis, cadmium, adsorption, isotherm, spectroscopy.

\section{INTRODUCTION}

The heavy metals contamination into the environment caused by human activities (industry, agriculture, and mining) is a crucial worry for water, wastewater, and soils around the world (Usman et al., 2016). There are ecological and human health risks associated with toxic metals in water (Laniyan and Adewumi, 2021). There is a significant positive correlation between the toxic metal contents ( $\mathrm{Cd}$ for example) in the soil and those in the plants (Ugulu et al., 2021). Human activities (industry, transportation, and agriculture) have caused toxic $\mathrm{Cd}$ pollution resulting in ecological risk to agricultural soil, the $\mathrm{Cd}$ ratio was exceeding the soil background value with $99.9 \%$ (Duan et al., 2021).

Usman et al. (2016) mentioned that Cadmium is very toxic to living organisms even at low concentrations and could be carcinogenic if present in water; thus, its remediation is necessary. Many techniques were used for removing heavy metals (ion-exchange, membrane filtration, adsorption, electrochemical, and chemical precipitation), each method has inherent advantages as well as one or more issues, challenges and limitations in application (Manna and Bhaumik, 2021).

The adsorption method has advantages in treating wastewater from heavy metals 
regarding its high efficiency and cheap cost (Cheng et al., 2021; Lucaci et al., 2020). The common adsorbent for heavy metal remediation from water is the activated carbon, which is expensive. Therefore, more attention needs to be devoted by scientists to searching low cost adsorbent with high ability to retain metals, which is one of the current challenges for scientists (Ungureanu et al., 2020).

Date trees are one of the most abundant trees worldwide, which generated beneficial wastes that can be reused in industry (Nasir et al., 2021). Mathijsen (2021) reported that the Middle East and North Africa regions have an estimated 140 million date trees. In consequence, the consumption of dates is common in these countries on a daily basis, in addition to its entry into the food industries. Thus, huge quantities of date seeds are produced and can be used in industries as a raw and ecofriendly material. Therefore, date seeds could be a good resource for biochar production, which can be used as metal absorbent. Biochar showed a high potential in treating wastewater from heavy metals due to its high porosity and the existence of various functional groups (Cheng et al., 2021). Other studies claimed that biochar was effective with high affinity to remove heavy metals from aqueous environment $(\mathrm{Li}$ et al., 2017; Trakal et al., 2014). Within context, many adsorbents were produced through pyrolysis and applied as an effective cheap technique for water purification (De Gisi et al., 2016). Singh et al. (2021) reported that the biochars produced from organic waste can be used as good green sorbents for the remediation of heavy metals from aquatic environment. However, the efficiency of biochar for removal of heavy metals from aqueous solutions dependent mainly on its physical and chemical properties that can be controlled by many factors including raw material source and the pyrolysis conditions (Zhao et al., 2021).

In spite of the worldwide use of biochar as a remediation agent for the environment, more studies regarding the raw material suitability for biochar production, optimization of biochar production to achieve the best physicochemical characteristics as adsorbent agent, are needed. Therefore, this study was aimed to produce biochars from date seeds and to evaluate its efficiency on Cd removal of from aqueous solutions.

\section{MATERIAL AND METHODS}

\section{Raw materials and sample preparation}

Date seeds (DS) were obtained locally after removing the date fruits. The seeds were washed with deionized water and air-dried until reaching constant weight. The seed were then stored in desiccator for biochar production and further analysis.

\section{Date seeds physicochemical characteristics}

The seeds were weighted initially to obtain the wet weight, and then dried for $24 \mathrm{~h}$ at $105^{\circ} \mathrm{C}$ in an oven. The dried seed were then turned to ashes by pyrolysis using muffle furnace at 350,450 , and $550^{\circ} \mathrm{C}$ for $2 \mathrm{~h}$. The physicochemical parameters: moisture content, ash content, and organic matter were calculated using the equations $1,2,3$, and 4 according to (Babu et al., 2021 and Liu et al., 2019). Fixed carbon content was measured by calculating the remaining residues including the non-volatile and minerals after releasing the volatile matter (Mahdi et al., 2015).

$$
\begin{gathered}
\text { Moisture content }(\%)=\left(\frac{\text { wet }_{w t}-D r y_{w t}}{\text { Wet }_{w t}}\right) * 100 \% \\
\text { Ash content }(\%)=\left(\frac{A s h_{w t}}{D r y_{w t}}\right) * 100 \% \\
\text { Organic matter }=\text { Dry }_{w t}-A s h_{w t} \\
\text { Organic matter }(\%)=\left(\frac{\text { organic matter }_{\text {Dry }}}{\text { Ort }}\right) * 100 \%
\end{gathered}
$$

where: $w^{2} t_{w t}$ is the sample weight before drying, $D r y_{w t}$ is the sample weight after drying at $105^{\circ} \mathrm{C}$ for $24 \mathrm{~h}$, and $A s h_{w t}$ is the ash weight after pyrolysis for $2 \mathrm{~h}$.

\section{Biochar production and analysis}

The DS biochar was produced by pyrolysis of dried dates seeds in absence of oxygen using closed porcelain crucible in the muffle furnace at different temperatures 350,450 , and $550^{\circ} \mathrm{C}$ for $2 \mathrm{~h}$ (Jerley et al., 2021). The DS biochar has been crushed and sieved to particle size of $2 \mathrm{~mm}$ to be used in the later experiments. The yield of DS biochar was measured using equation 5 (Mohawesh et al., 2018 and Angin, 2013).

$$
\text { Biochar yield }(\%)=\left(\frac{\text { Weight of biochar }}{\text { Weight of dry sample }}\right) * 100 \%
$$

The microstructure and morphology of DS biochar was investigated by scanning electron microscopy (SEM) with energy dispersive X-ray analysis (EDX). 
The porosity and water absorption of the DS biochar were measured following the Archimedes method according to the standard method (ASTM C20) as mentioned by (Sutcu et al., 2019) by placing the well-dried DS biochar in boiling water for $2 \mathrm{~h}$ then soaked in water for $12 \mathrm{~h}$. Thereafter, equations 6 and 7 were used to determine the above-mentioned parameters:

$$
\begin{gathered}
\text { Porosity }(\%)=\left(\frac{\text { Open pore volume }}{\text { Total volume }}\right) * 100 \% \\
=\left(\frac{\text { Sat } t_{w t}-\text { Dry }}{\text { Sat }_{w t}-S u s_{w t}}\right) * 100 \%
\end{gathered}
$$

where: Dry $y_{w t}$ is the biochar weight after drying at $105^{\circ} \mathrm{C}$ for $24 \mathrm{~h}, \mathrm{Sat}_{w t}$ is the biochar saturated weight after boiling in water for $2 \mathrm{~h}$, and $\mathrm{Sus}_{w t}$ is the biochar suspended weight while suspending in water for $12 \mathrm{~h}$.

The $\mathrm{pH}$ value for the DS biochar was investigated according to Greenberg (2005). Bulk density was determined using an analytical balance and a graduated cylinder. The bulk density was detected by weighing the well-known volume of uncompacted DS biochar particles after taping the cylinder vigorously on a wooden table until reaching a constant volume. It was calculated as mass of the biochar particles per volume of uncompacted biochars (Liao and Thomas, 2019).

For elemental content, the biochar was analyzed by means of (Inductively coupled plasmamass spectrometry, ICP-MS). For that purpose, each of the biochar samples produced under different temperatures $\left(350,450\right.$, and $\left.550^{\circ} \mathrm{C}\right)$, were pyrolyzed in the muffle furnace at $550^{\circ} \mathrm{C}$ for $2 \mathrm{~h}$ to produce ash. Thereafter, $1 \mathrm{ml}$ of Bismuth $200 \mathrm{ppm}$ was added to $0.1 \mathrm{~g}$ of each ash sample into teflon vials as external standard. The samples were digested by concentrated acid mixture $\mathrm{HNO}_{3}: \mathrm{HCl}$ : HF with ratio of 2:6:2(v/v), respectively. The digestion was carried out using hotplate at $75^{\circ} \mathrm{C}$, $100^{\circ} \mathrm{C}, 120^{\circ} \mathrm{C}, 150^{\circ} \mathrm{C}$, and $200^{\circ} \mathrm{C}$ for $5,10,10$, 10 , and $20 \mathrm{~min}$, respectively. The digested samples were filtered through syringe filters $0.45 \mu \mathrm{m}$ pore size (PTFE, Sartorius, Göttingen/Germany), the filtrate was then diluted to $50 \mathrm{ml}$ by $2 \%$ nitric acid and analyzed for elements by means of ICPMS (ELAN 9000, Perkin-Elmer SCIEX).

\section{Sorption isotherm, adsorption, and desorption for Cd by DS biochar}

Cadmium was chosen to be a model to study the heavy metal adsorption by DS biochar for two reasons. First; it was not detected within the DS biochar, and the second; it is always detected in industrial wastewaters; therefore, it could find its way into the environment, food chain and thus human systems.

The DS biochar produced at 350, 450, and $550^{\circ} \mathrm{C}$ were tested for the sorption isotherm experiment. The adsorption of Cd by DS biochar was investigated for the sorption capacity and equilibrium. For that reason, a stock solution of Cd with concentration of $10 \mathrm{mmol}$ was prepared by dissolving the proper weight of cadmium nitrate (Merck, Darmstadt, Germany) in one liter of deionized water. 0.5 gram of DS biochar was added to $100 \mathrm{ml}$ flasks volume containing $50 \mathrm{ml}$ of different $\mathrm{Cd}$ concentrations $0.01,0.02,0.05$, 0.1 and $0.2 \mathrm{mmol}$, the $\mathrm{pH}$ was adjusted to 7 . All flasks were rotated with $50 \mathrm{rpm}$ at $25^{\circ} \mathrm{C}$ overnight and followed by centrifugation for $10 \mathrm{~min}$ at 3500 $\mathrm{rpm}$. The equilibrium solutions (supernatants) were filtered by $0.45 \mu \mathrm{m}$ syringe filters (Palágyi et al., 2005). The filtrate solutions were acidified with $2 \% \mathrm{HNO}_{3}(\mathrm{v} / \mathrm{v})$ and analyzed for Cd using Atomic Absorption Spectroscopy (Shimadzu, AA7000, Japan). After collecting and filtrating the supernatant, all flasks were weighted again with the DS biochar and the remaining cadmium solution. The remaining cadmium solution that will be used later in desorption calculations was calculated by subtracting the weight of dried DS biochar and the weight of empty flasks from the total weight, to be used in the calculations of desorption later.

The experiments of desorption were performed for the DS biochar that was produced at $550^{\circ} \mathrm{C}$ and used previously in the adsorption experiments due to its physicochemical properties regarding $\mathrm{WHC}$ and porosity percentage as well as its higher ability to adsorb more $\mathrm{Cd}$ than the biochars produced at 350 and $450^{\circ} \mathrm{C}$. For that reason, $5 \mathrm{~mL}$ of ammonium nitrate with 1 M concentration (Merck, Darmstadt, Germany) were added to the flasks containing the DS biochar from the adsorption experiment. The mixtures were rotated for $24 \mathrm{~h}$ with $50 \mathrm{rpm}$ at $25^{\circ} \mathrm{C}$ then centrifuged for $10 \mathrm{~min}$ at $3500 \mathrm{rpm}$. The supernatants were filtered by $0.45 \mu \mathrm{m}$ syringe filters (Rao et al., 2008; Palágyi et al., 2005) and then diluted with deionized water with ratio of 1:4 (v/v), and acidified with $2 \% \mathrm{HNO}_{3}(\mathrm{v} / \mathrm{v})$. The supernatants were then analyzed for $\mathrm{Cd}$ using Atomic Absorption Spectroscopy (Shimadzu, AA-7000, Japan). The amount of desorbed Cd was measured by subtracting the amount of $\mathrm{Cd}$ 
concentration in the $\mathrm{Cd}$ solution from the adsorption experiment from a mount of $\mathrm{Cd}$ concentration in the desorption solution.

\section{RESULTS AND DISCUSSION}

\section{Physicochemical characteristics of the date seeds (DS)}

The results of physicochemical parameters of DS as a raw material for biochar production showed a low moisture content $(8.92 \%)$, low ash yield (1.05\%), high volatile matter (78.3\%), high bulk density $\left(0.512 \mathrm{~g} / \mathrm{cm}^{3}\right)$, acidic with $\mathrm{pH}$ 4.6 , and porosity (23\%). The nitrogen and fixed carbon percentages were 2.13 and $21.7 \%$, respectively (Table 1).

These results were in agreement with Mahdi et al. (2015) and El May (2012), who found that the water content of date seed were 8.95 and $5-10 \%$, respectively. Same findings for the ash content were reported by Mahdi et al. (2015) and Bouchelta et al. (2008) who reported that the ash content of date seeds was 1.14 and $1-2 \%$, respectively. The results of bulk density, volatile matter, and fixed carbon were proportional to the results of Mahdi et al. (2015) who found bulk density of $0.504 \mathrm{~g} / \mathrm{cm}^{3}$, volatile matter of $65 \%$, and fixed carbon of $24.87 \%$.

On the basis of the above-mentioned finding from the current study, it was found that the date seeds are a good sourced raw material for biochar production.

\section{Biochar characteristics}

The results of DS biochar analysis produced under different pyrolysis temperatures (350, 450 , and $550^{\circ} \mathrm{C}$ ) showed an increase in the

Table 1. Physicochemical parameters of the date seeds (DS) as a raw material for biochar production

\begin{tabular}{|l|c|}
\hline \multicolumn{1}{|c|}{ Parameters } & Value \\
\hline Water content (\%) & $8.92 \pm 0.5$ \\
\hline Ash of dry weight (\%) & $1.05 \pm 0.05$ \\
\hline Nitrogen (\%) & $2.13 \pm 0.1$ \\
\hline Volatile matter of dry weight (\%) & $78.3 \pm 4$ \\
\hline Fixed carbon of dry weight $(\%)$ & $21.7 \pm 1.2$ \\
\hline Bulk density $\left(\mathrm{g} / \mathrm{cm}^{3}\right)$ & $0.512 \pm 0.03$ \\
\hline pH & $4.6 \pm 0.3$ \\
\hline Porosity (\%) & $23 \pm 1.2$ \\
\hline
\end{tabular}

pH (5.7-7.8), organic matter (75.34-98.96\%), fixed carbon (43.7-57.4\%), ash content (2.3$4.6 \%$ ), porosity $(31-69 \%)$, and the water holding capacity (WHC) $(29.7-58.1 \%)$ with the increment of pyrolysis temperature from 350 to $550^{\circ} \mathrm{C}$. Meanwhile, a decrease was observed in the bulk density $(0.475-0.358 \%)$, biochar yield (39.7-23.6\%), and nitrogen content (0.74$0.58 \%$ ) with the increment of pyrolysis temperature from 350 to $550^{\circ} \mathrm{C}$, respectively (Table 2) and (Figure $1 \mathrm{~A}$ and $\mathrm{B}$ ).

These findings were in agreement with Usman et al. (2015), who found that the yield of date seeds biochar was decreased from $49.97 \%$ at $300^{\circ} \mathrm{C}$ to $30.88 \%$ at $600^{\circ} \mathrm{C}$ with an increment in fixed carbon from 45.49 to 72.44 and ash content from 14.42 to $20.71 \%$. Mahdi et al. (2015) find out that the $\mathrm{pH}$, bulk density, and porosity of date seeds biochar were directly proportional to the pyrolysis temperature, meanwhile, the biochar yield was inversely proportional. Same trend was observed regarding the effect of pyrolysis temperature on biochar production from safflower seeds, they reported a decrease in biochar yield, increase in $\mathrm{pH}$, ash, and fixed carbon with the increase of pyrolysis temperature by Angin (2013).

The SEM-EDX analyses of the DS biochar pyrolyzed at different temperatures $(350,450$, and $550^{\circ} \mathrm{C}$ ) were shown in Figure 2.

The microstructure and surface morphology structures of the DS biochar showed porous surfaces that were caused by volatilization of organic materials. The number of pores and its appearance as deep channels in biochars became clearer with increment of pyrolysis temperature. These results confirm the previous results regarding the increase in porosity proportional to the pyrolysis temperatures, which increased from 31 to $69 \%$ when the pyrolysis temperature increased from 350 to $550^{\circ} \mathrm{C}$ (Table 2).

The results from the current study showed that all of the elements concentrations in the DS biochar were increased with pyrolysis temperature with exception of $\mathrm{S}$, as compared with the raw material (Table 3). This could mainly have related to concentrated of these elements in DS biochar samples due to temperature. Thus, these elements could not be lost by volatilization (Al-Wabel et al., 2013; Novak et al., 2009). Meanwhile, the decrease in $\mathrm{S}$ with increment of pyrolysis temperature could be interpreted by sulfur volatilization during pyrolysis (Al-Wabel et al., 2013). 
Table 2. Physicochemical parameters of the DS biochar produced under different pyrolysis temperatures. The results were expressed by mean $\pm \mathrm{SD}, \mathrm{n}=3$

\begin{tabular}{|l|c|c|c|}
\hline \multirow{2}{*}{\multicolumn{1}{|c|}{ Parameters of DS biochar }} & \multicolumn{3}{|c|}{ Pyrolysis temperatures $\left({ }^{\circ} \mathrm{C}\right)$} \\
\cline { 2 - 4 } & 350 & 450 & 550 \\
\hline Organic matter (\%) & $75.34 \pm 4$ & $83.27 \pm 4.2$ & $98.96 \pm 5$ \\
\hline Fixed carbon (\%) & $43.7 \pm 2$ & $48.3 \pm 2.5$ & $57.4 \pm 3$ \\
\hline Bulk density (g/cm $\left.{ }^{3}\right)$ & $0.475 \pm 0.02$ & $0.407 \pm 0.02$ & $0.358 \pm 0.02$ \\
\hline Porosity (\%) & $31 \pm 1.5$ & $58 \pm 3$ & $69 \pm 3.5$ \\
\hline Biochar yield (\%) & $39.7 \pm 2$ & $31.5 \pm 1.6$ & $23.6 \pm 1.2$ \\
\hline pH & $5.7 \pm 0.2$ & $6.9 \pm 0.1$ & $7.8 \pm 0.1$ \\
\hline Ash of biochar (\%) & $2.3 \pm 0.12$ & $3.1 \pm 1.6$ & $4.6 \pm 0.23$ \\
\hline Nitrogen (\%) & $0.74 \pm 0.04$ & $0.65 \pm 0.03$ & $0.58 \pm 0.03$ \\
\hline Water holding capacity (WHC) (\%) & $29.7 \pm 1.5$ & $46.3 \pm 2$ & $58.1 \pm 3$ \\
\hline
\end{tabular}

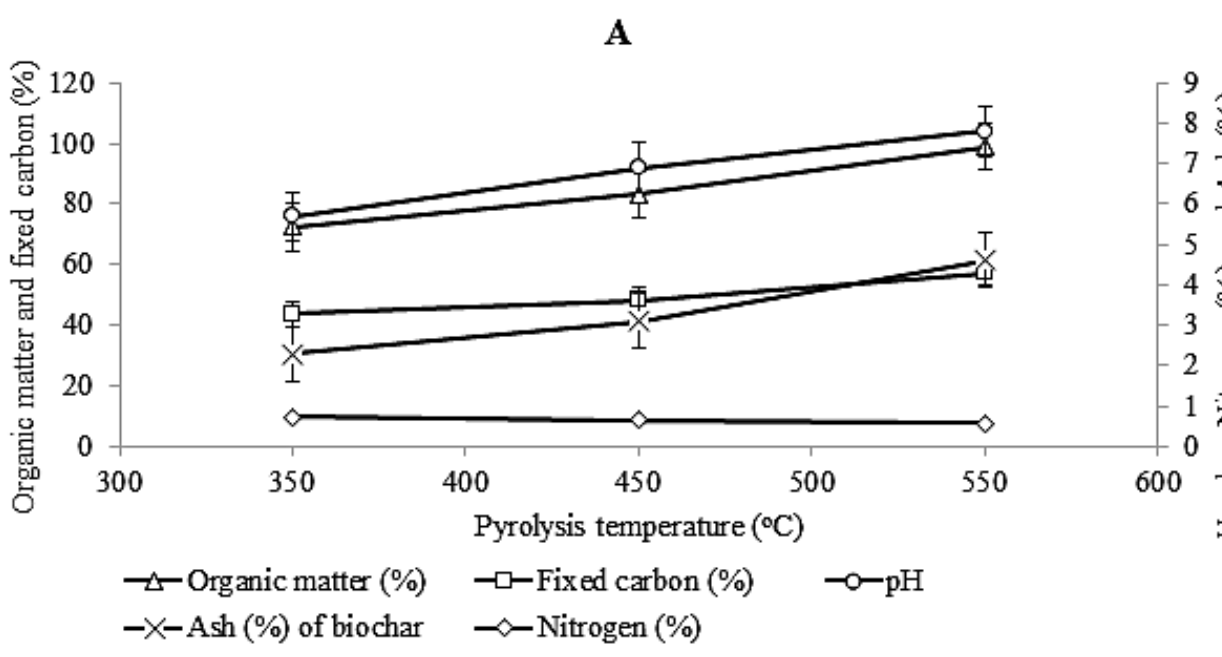

B

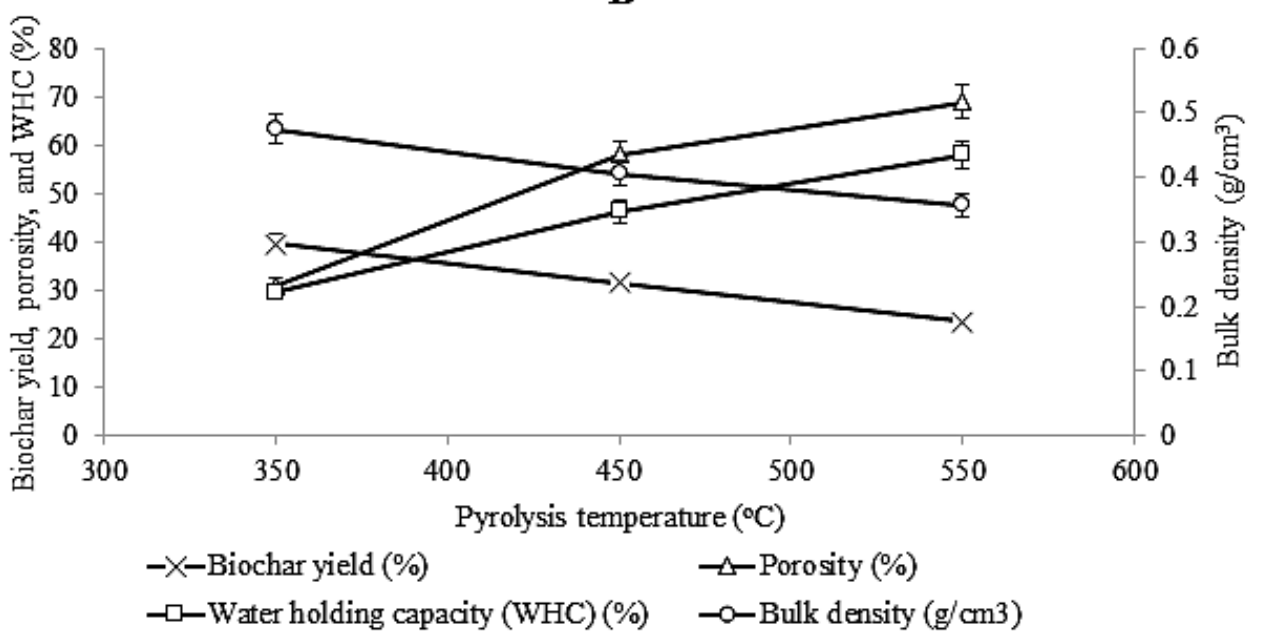

Figure 1. Effect of different pyrolysis temperatures $\left(350,450\right.$, and $\left.550^{\circ} \mathrm{C}\right)$ on the physicochemical parameters of the DS biochar; A: Organic matter, fixed carbon, $\mathrm{pH}$, ash content, and nitrogen content, B: Biochar yield, porosity, water holding capacity (WHC), and bulk density 

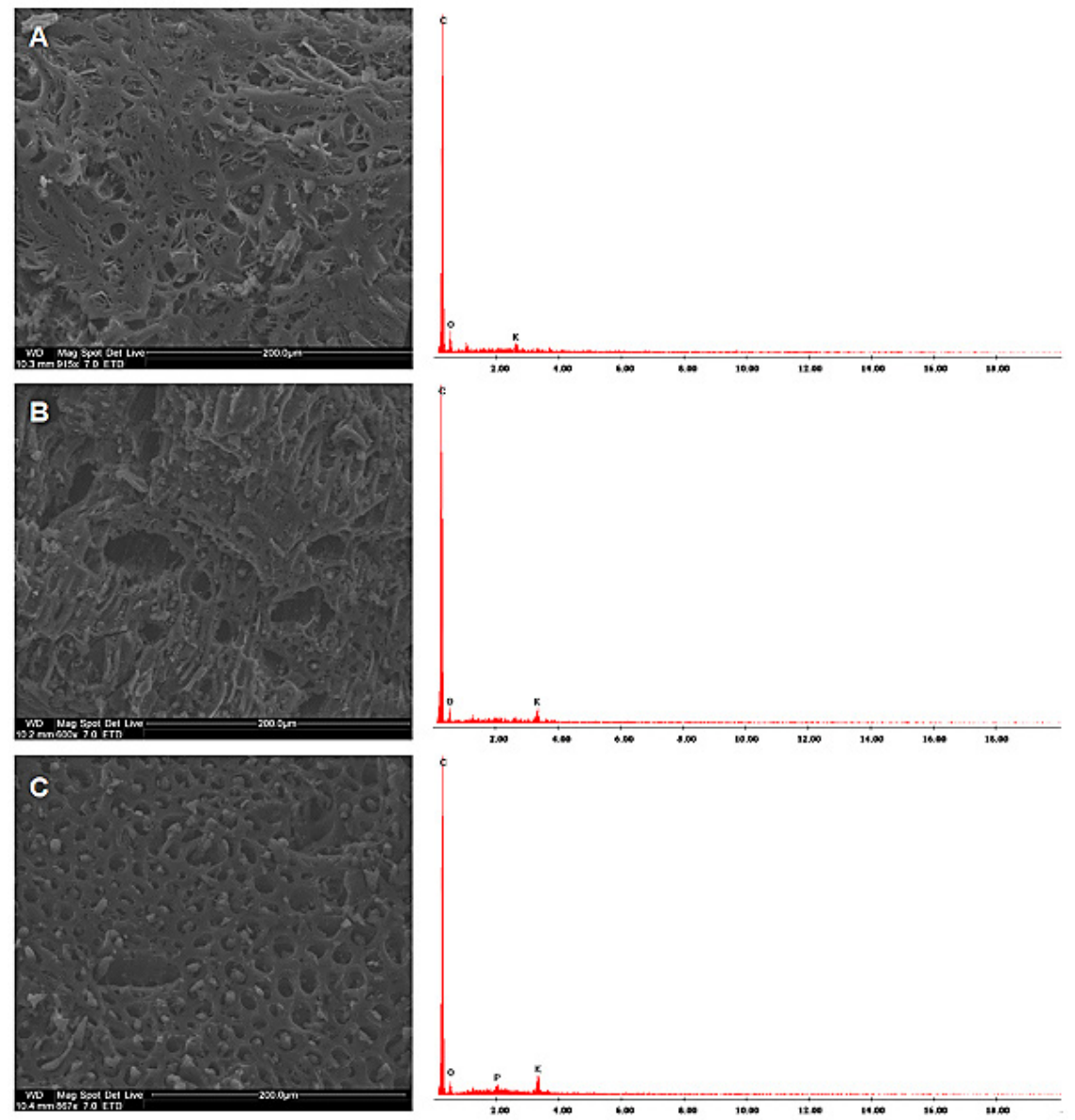

Figure 2. SEM - EDX analysis of DS biochar produced at different temperatures; A) $350^{\circ} \mathrm{C}$, B) $450^{\circ} \mathrm{C}$, and C) $550^{\circ} \mathrm{C}$

Table 3. Elemental content of date seeds (DS) as raw material and DS biochar produced under different pyrolysis temperatures, the results were expressed by mean $\pm \mathrm{SD}, \mathrm{n}=3$

\begin{tabular}{|c|c|c|c|c|}
\hline \multirow{2}{*}{ Elements } & \multicolumn{4}{|c|}{ Elemental content (mg/kg) } \\
\cline { 2 - 5 } & $\begin{array}{c}\text { Dates seeds (DS) } \\
\text { as raw material }\end{array}$ & $\begin{array}{c}\text { DS biochar produced } \\
\text { at } 350^{\circ} \mathrm{C}\end{array}$ & $\begin{array}{c}\text { DS biochar produced } \\
\text { at } 450{ }^{\circ} \mathrm{C}\end{array}$ & $\begin{array}{c}\text { DS biochar produced } \\
\text { at } 550^{\circ} \mathrm{C}\end{array}$ \\
\hline $\mathrm{Na}$ & $102 \pm 4$ & $442 \pm 49$ & $457 \pm 39$ & $472 \pm 42$ \\
\hline $\mathrm{K}$ & $5200 \pm 401$ & $14374 \pm 426$ & $14450 \pm 355$ & $6349 \pm 750$ \\
\hline $\mathrm{Ca}$ & $2802 \pm 49$ & $5931 \pm 864$ & $6219 \pm 924$ & $3145 \pm 248$ \\
\hline $\mathrm{Mg}$ & $1102 \pm 36$ & $2713 \pm 201$ & $2924 \pm 294$ & $525 \pm 90$ \\
\hline $\mathrm{Fe}$ & $91.5 \pm 5$ & $432 \pm 26$ & $435 \pm 57$ & $35 \pm 5$ \\
\hline $\mathrm{Mn}$ & $6.7 \pm 0.3$ & $11 \pm 1$ & $23 \pm 3$ & $5225 \pm 47$ \\
\hline $\mathrm{P}$ & $1837 \pm 31$ & $5039 \pm 52$ & $5118 \pm 61$ & $492 \pm 17$ \\
\hline $\mathrm{S}$ & $650 \pm 24$ & $602 \pm 23$ & $543 \pm 15$ & $46 \pm 8$ \\
\hline $\mathrm{Zn}$ & $7.9 \pm 0.1$ & $24 \pm 0.4$ & $38 \pm 5$ & $12 \pm 2$ \\
\hline $\mathrm{Ba}$ & B.D* & $8 \pm 1$ & $10 \pm 1$ & $63 \pm 11$ \\
\hline $\mathrm{Cr}$ & B.D & $46 \pm 5$ & $60 \pm 11$ & $23 \pm 4$ \\
\hline $\mathrm{Cu}$ & B.D & $15 \pm 2$ & $21 \pm 2$ & $11 \pm 2$ \\
\hline $\mathrm{Ni}$ & B.D & $4 \pm 0.4$ & $8 \pm 1$ & $4 \pm 0.4$ \\
\hline $\mathrm{Pb}$ & B.D & B.D & $3 \pm 0.3$ & $68 \pm 12$ \\
\hline $\mathrm{Ti}$ & B.D & $26 \pm 2$ & $47 \pm 6$ & $12 \pm 1$ \\
\hline $\mathrm{V}$ & B.D & $8 \pm 1$ & & \\
\hline $\mathrm{B}$ & & & \\
\hline
\end{tabular}

*B.D - Below detection limit. 


\section{Adsorption isotherm for $\mathrm{Cd}$ (Langmuir and Freundlich)}

Cadmium is frequently detected in the wastewaters produced from batteries, metal, petroleum, and pesticides industries, etc. The contaminated water with cadmium could enter the environment, food chain, and thus human system. Hence, cadmium was chosen to be a model for heavy metal adsorption by DS biochar.

The Freundlich and Langmuir isotherms were applied for modeling the data of adsorbed cadmium on DS biochar. The adsorption was fitted closely to both isotherms models. The $\mathrm{R}^{2}$ of both models were 0.9924 and 0.9628 for Langmuir and Freundlich adsorption isotherms, respectively, for the DS biochar produced at $550^{\circ} \mathrm{C}$. Meanwhile, they were 0.9893 and 0.9569 for the DS biochar on $450^{\circ} \mathrm{C}$ and 0.9909 and 0.9535 for the DS biochar on $350^{\circ} \mathrm{C}$. Therefore, the Langmuir model was considered the better apt of data, as an evidence of higher $\mathrm{R}^{2}$ value (Figures 3, 4, and 5).

These findings were in agreement with Okeola and Odebunmi (2010) who found that Langmuir $\left(\mathrm{R}^{2}\right.$ $=0.9999)$ was more suitable than Freundlich $\left(R^{2}=\right.$
0.9922) to their data when studding the methylene blue adsorption by agro-waste charcoal. The adsorption of $\mathrm{Cu}$ on starch-based polymer was found to be more fitted with Langmuir $\left(\mathrm{R}^{2}=0.9995\right)$ than Freundlich $\left(\mathrm{R}^{2}=0.8199\right)$ (Zheng et al., 2010).

Therefore, Langmuir was employed to assess the adsorption data in the current study as reason of having higher $\mathrm{R}^{2}$ than Freundlich.

\section{Adsorption and desorption}

The adsorption experiments for Cd by DS biochar were carried by spiking deionized water with different concentrations of cadmium. The Langmuir and Freundlich equations were applied for the data analysis. The DS biochar produced at 350, 450, and $550^{\circ} \mathrm{C}$ showed the capability to adsorb Cd with 667 , 714 , and $833 \mathrm{mg} / \mathrm{kg}$ for Langmuir and 244, 256, and 312 for Freundlich, respectively (Table 4).

The results showed that the adsorption capacity of Cd by DS biochar was increased proportionally with the biochar production temperature. These findings were in agreement with Mahdi et al. (2017), who found out that the ability of biochar to remove methylene blue from aqueous solutions

A

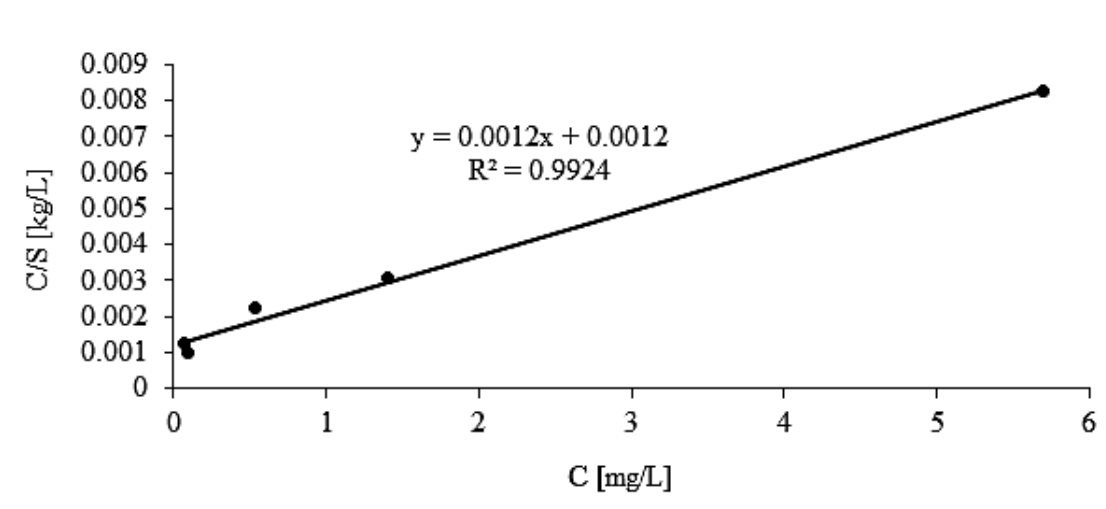

B

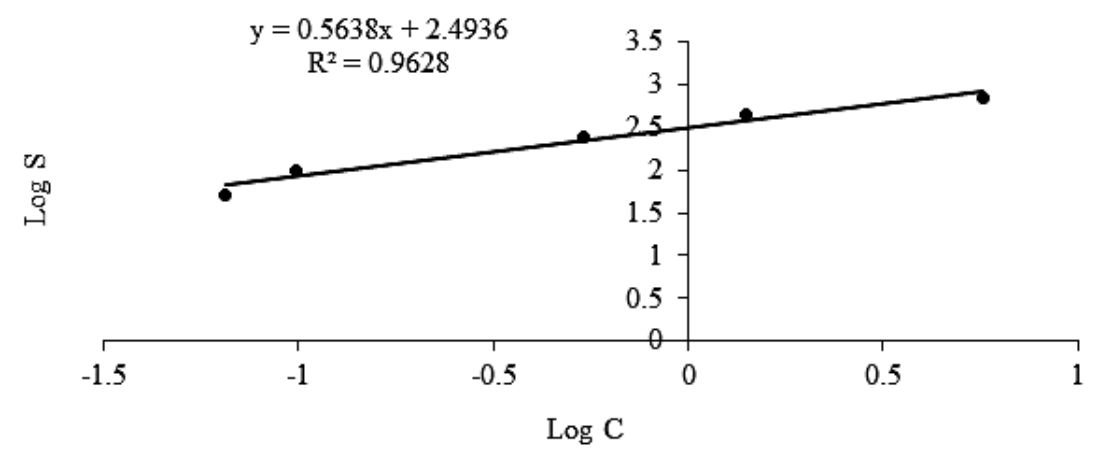

Figure 3. Linear fitting data plots determined for Cd adsorption on the DS biochar produced at $550^{\circ} \mathrm{C}$

(A) Langmuir (B) Freundlich (S) Mass of DS biochar (kg); (C) Equilibrium concentration 
A

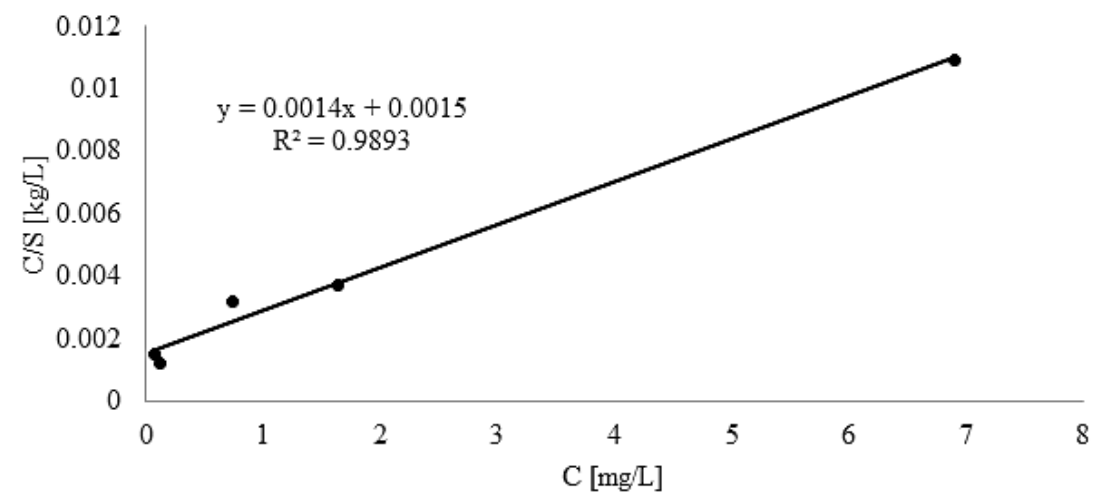

B

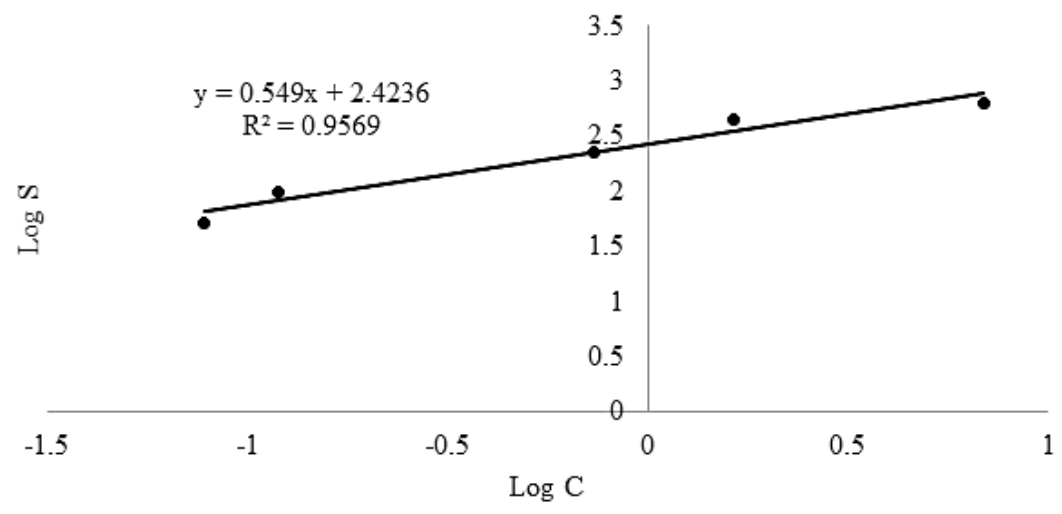

Figure 4. Linear fitting data plots determined for Cd adsorption on the DS biochar produced at $450^{\circ} \mathrm{C}$

(A) Langmuir (B) Freundlich (S) Mass of DS biochar (kg); (C) Equilibrium concentration

A

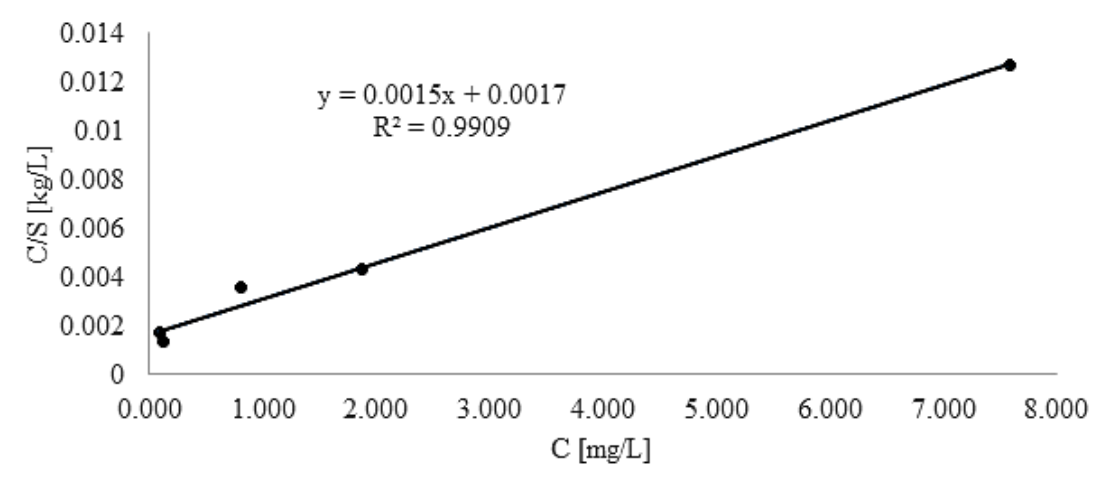

B

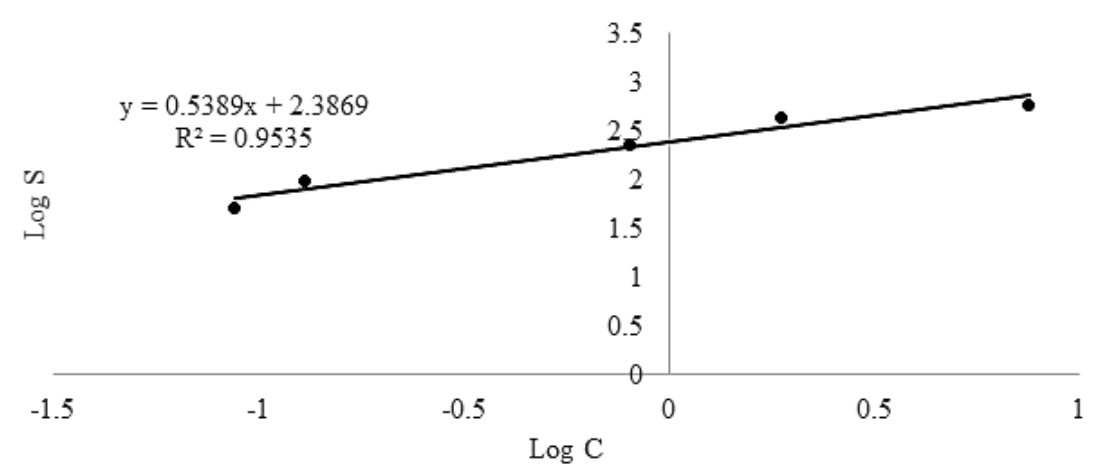

Figure 5. Linear fitting data plots determined for Cd adsorption on the DS biochar produced at $350^{\circ} \mathrm{C}$ (A) Langmuir (B) Freundlich (S) Mass of DS biochar (kg); (C) Equilibrium concentration 
Table 4. Cadmium adsorption by DS biochar produced at different temperatures using adsorption Langmuir isotherm equations

\begin{tabular}{|c|c|c|c|}
\hline \multirow{2}{*}{ Isotherm equations } & \multicolumn{3}{|c|}{ Cadmium adsorption by DS biochar produced at different pyrolysis temperatures (mg/kg) } \\
\cline { 2 - 4 } & $550^{\circ} \mathrm{C}$ & $450^{\circ} \mathrm{C}$ & $350^{\circ} \mathrm{C}$ \\
\hline Langmuir & 833 & 714 & 667 \\
\hline Freundlich & 312 & 256 & 244 \\
\hline
\end{tabular}

correlated positively with pyrolysis temperature. The removal efficiency of $\mathrm{Pb}$ was the highest at the high pyrolysis temperature among the tested date seed biochars (Mahdi et al., 2018). Many works mentioned that the adsorption capability of different biochars was improved as a function of pyrolysis time and temperature.

As expected, the Langmuir equation showed higher Cd adsorption by DS biochar compared with the Freundlich equation. These findings confirm what was mentioned in the previous section regarding isotherm experiment results, where the $\mathrm{R}^{2}$ of Langmuir was higher than in the case of Freundlich. This was in agreement with Banat et al. (2003) who found the Langmuir and Freundlich isotherm models were used successfully for the mathematical description of the sorption of cadmium ions onto carbonized date pits.

For desorption/adsorption experiment, it was carried out using the DS biochar produced at $550^{\circ} \mathrm{C}$ as a reason of its higher ability to adsorb $\mathrm{Cd}$ more than the biochars produced at 350 and $450^{\circ} \mathrm{C}$. It was found that the adsorption of $\mathrm{Cd}$ by DS biochar was directly proportional to the $\mathrm{Cd}$ concentrations. It was increased from $0.009 \mathrm{mmol} / 0.5 \mathrm{~g}$ at $0.01 \mathrm{mmol}$ Cd to $0.12 \mathrm{mmol} / 0.5 \mathrm{~g}$ at $0.2 \mathrm{mmol} \mathrm{Cd}$ concentration (Table 5 and Figure 6). The Cd desorption from DS biochar was increased proportionally to $\mathrm{Cd}$ concentrations from 0.01 to $0.05 \mathrm{mmol}$. Above $0.05 \mathrm{mmol}$, the desorption was almost constant regardless to the concentration of $\mathrm{Cd}$. The desorption/adsorption ratio of $\mathrm{Cd}$ from the DS biochar was constant also with about 16\% (Table 5 and Figure 6).

These findings confirmed a high retention potential for adsorbed Cd by the DS biochar. Ahmad et al. (2012) mentioned that carbonized date seed have a high affinity to bind heavy metals, thus able to remove heavy metals from wastewater. Usman et al. (2016) found that the date palm biochar

Table 5. Cadmium adsorption, desorption, and desorption/adsorption ratio by $0.5 \mathrm{~g}$ biochar, the results were expressed by mean $\pm \mathrm{SD}, \mathrm{n}=3$

\begin{tabular}{|c|c|c|c|}
\hline Cd conc. mmol & Adsorbed Cd to biochar $(\mathrm{mmol})$ & Desorbed Cd from biochar $(\mathrm{mmol})$ & Cd des/ads $(\%)$ \\
\hline 0.01 & $0.01 \pm 0.0006$ & $0.002 \pm 0.0001$ & $15.5 \pm 0.78$ \\
\hline 0.02 & $0.02 \pm 0.001$ & $0.003 \pm 0.0002$ & $15.5 \pm 0.77$ \\
\hline 0.05 & $0.069 \pm 0.0035$ & $0.011 \pm 0.0006$ & $15.9 \pm 0.79$ \\
\hline 0.1 & $0.09 \pm 0.0045$ & $0.015 \pm 0.0007$ & $16.4 \pm 0.82$ \\
\hline 0.2 & $0.12 \pm 0.006$ & $0.02 \pm 0.001$ & $16.7 \pm 0.83$ \\
\hline
\end{tabular}

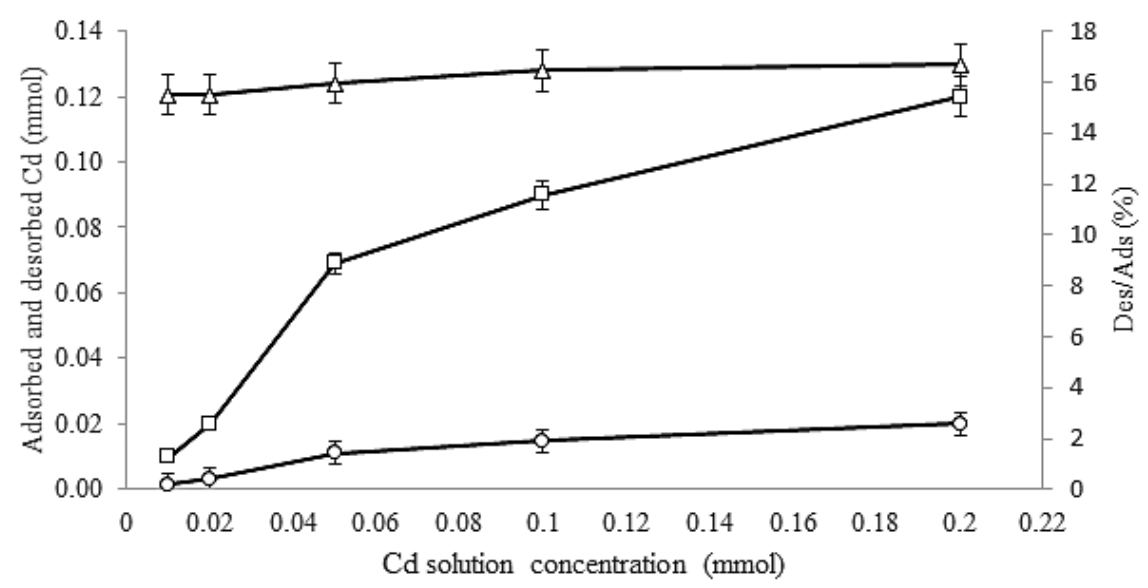

$\neg-$ Adsorbed Cd to biochar (mmol) $\multimap-$ Desorbed Cd from biochar (mmol) $\triangle-\mathrm{Cd}$ des/ads (\%)

Figure 6. Cadmium adsorption, desorption, and desorption/adsorption ratio by $0.5 \mathrm{~g}$ DS biochar 
produced at $700^{\circ} \mathrm{C}$ was effective in removing $\mathrm{Cd}$ from aqueous solution with adsorption capacity of $43.58 \mathrm{mg} / \mathrm{g}$ based on the Langmuir model. The ability of DS biochar to treat water by adsorbing $\mathrm{Cd}$ from the contaminated water was investigated in the current study in the adsorption experiment with artificial contaminated water, which was spiked with different $\mathrm{Cd}$ concentrations.

\section{CONCLUSIONS}

The current study investigated the suitability of date seeds (DS) as a raw matter for biochar production and its ability to be used in water remediation. Therefore, DS biochar was produced under different pyrolysis temperatures. DS biochar was evaluated according to its physicochemical characteristics. The biochar produced at $550^{\circ} \mathrm{C}$ was investigated for removing $\mathrm{Cd}$ from contaminated water, it was chosen according to its high porosity as well as WHC. The results found that the date seeds are a good source of raw material for biochar production. The DS biochar produced at $550^{\circ} \mathrm{C}$ was very active in terms of $\mathrm{Cd}$ removal from aqueous solutions, with low predilection toward releasing it again by desorption, which was almost $16 \%$. Moreover, Langmuir equation showed a high capability of DS biochar to adsorb Cd with $833 \mathrm{mg} / \mathrm{kg}$. Thus, it can be concluded that the DS biochar produced at $550^{\circ} \mathrm{C}$ could be considered as an active adsorbent for $\mathrm{Cd}$ removal from contaminated water. It is recommended to investigate and optimize the production of biochar from DS as raw matter at higher temperatures, as well as from different raw matters in any future studies. Moreover, its applications in water and soil remediation, and plant cultivation need to be in focus.

\section{Acknowledgements}

Grateful thanks to Prince Faisal Center for Dead Sea, Environmental and Energy Research, Mutah University for their help.

\section{REFERENCES}

1. Ahmad, T., Danish, M., Rafatullah, M., Ghazali, A., Sulaiman, O., Hashim, R., and Ibrahim, M. N. M. 2012. The use of date palm as a potential adsorbent for wastewater treatment: a review. Environmental Science and Pollution Research, 19(5), 1464-1484.
2. Al-Wabel, M. I., Al-Omran, A., El-Naggar, A. H., Nadeem, M., \& Usman, A. R. 2013. Pyrolysis temperature induced changes in characteristics and chemical composition of biochar produced from conocarpus wastes. Bioresource technology, 131, 374-379.

3. Angin, D. (2013). Effect of pyrolysis temperature and heating rate on biochar obtained from pyrolysis of safflower seed press cake. Bioresource technology, 128, 593-597.

4. Babu, A. T., Vijay, A. K., Bhanuvikraman, A. K., and Madhavan, A. 2021. A study on biochar Preparation and Characterization of Broiler's Poultry Litter. International Journal of Ecology and Environmental Sciences, 47(3), 209-218.

5. Banat, F., Al-Asheh, S., \& Al-Makhadmeh, L. 2003. Kinetics and equilibrium study of cadmium ion sorption onto date pits - an agricultural waste. Adsorption Science and Technology, 21(3), 245-260.

6. Bouchelta, C., Medjram, M. S., Bertrand, O., and Bellat, J. P. 2008. Preparation and characterization of activated carbon from date stones by physical activation with steam. Journal of Analytical and Applied Pyrolysis, 82(1), 70-77.

7. Cheng, S., Liu, Y., Xing, B., Qin, X., Zhang, C., and Xia, H. 2021. Lead and cadmium clean removal from wastewater by sustainable biochar derived from poplar saw dust. Journal of Cleaner Production, 128074.

8. De Gisi, S., Lofrano, G., Grassi, M., and Notarnicola, M. 2016. Characteristics and adsorption capacities of low-cost sorbents for wastewater treatment: A review. Sustainable Materials and Technologies, 9, 10-40.

9. Duan, K., Zhao, B., Zhang, S., and Ma, Y. 2021. Contamination characteristics, source analysis, and ecological risk assessment of toxic metals and metalloid in agricultural soil in Yuzhong, China (Vol. 50, No. 1, pp. 122-133).

10. El May, Y., 2012. Measurement of Gaseous and Particulate Pollutants during Combustion of Date Palm Wastes for Energy Recovery. Aerosol and Air Quality Research. doi:10.4209/aaqr.2012.03.0056

11. Jerley, A., Swetha, G., Harini, V., and Priscila, R. 2021. Effects of Biochar and Vermichar as a Soil Supplement to Improve Maize Plant Growth. Asian Journal of Advances in Research, 37-45.

12. Greenberg, A.E., Clescerl, L.S., Eaton, A.D. 2005. Standard methods for the examination of water and wastewater $21^{\text {th }}$ edition. American water works association/American public works association/water environment fedration. ISBN: 0875530478.

13. Laniyan, T. A., and Adewumi, A. J. 2021. Ecological and human health risk associated with potentially toxic metals in water from Ijero mining area, Southwest Nigeria. International Journal of Environmental Analytical Chemistry, 1-25. 
14. Liao, W., and Thomas, S. C. 2019. Biochar particle size and post-pyrolysis mechanical processing affect soil $\mathrm{pH}$, water retention capacity, and plant performance. Soil Systems, 3(1), 14.

15. Li, H., Dong, X., da Silva, E. B., de Oliveira, L. M., Chen, Y., and Ma, L. Q. 2017. Mechanisms of metal sorption by biochars: biochar characteristics and modifications. Chemosphere, 178, 466-478.

16. Liu, H., Chen, Y., Yang, H., Gentili, F. G., Söderlind, U., Wang, X., and Chen, H. 2019. Hydrothermal carbonization of natural microalgae containing a high ash content. Fuel, 249, 441-448.

17. Lucaci, A. R., Bulgariu, D., Ahmad, I., and Bulgariu, L. 2020. Equilibrium and kinetics studies of metal ions biosorption on alginate extracted from marine red algae biomass (callithamnion corymbosum sp.). Polymers, 12(9), 1888.

18. Mahdi, Z., El Hanandeh, A., and Yu, Q. J. 2015. Date palm (Phoenix Dactylifera L.) seed characterization for biochar preparation. In The 6th international conference on engineering, project, and production management (EPPM) (pp. 2-4).

19. Mahdi, Z., El Hanandeh, A., and Yu, Q. 2017. Influence of pyrolysis conditions on surface characteristics and methylene blue adsorption of biochar derived from date seed biomass. Waste and Biomass Valorization, 8(6), 2061-2073.

20. Mahdi, Z., Qiming, J. Y., and El Hanandeh, A. 2018. Removal of lead (II) from aqueous solution using date seed-derived biochar: batch and column studies. Applied Water Science, 8(6), 1-13.

21. Manna, M. S., and Bhaumik, C. 2021. Opportunities and Challenges in Heavy Metal Removal from Water. In Remediation of Heavy Metals (pp. 347-366). Springer, Cham.

22. Mathijsen, D. 2021. The challenging path to add a promising new bio-fiber from an overlooked source to our reinforcement toolbox: Date palm fibers. Reinforced Plastics, 65(1), 48-52.

23. Mohawesh, O., Coolong, T., Aliedeh, M., and Qaraleh, S. 2018. Greenhouse evaluation of biochar to enhance soil properties and plant growth performance under arid environment. Bulg. J. Agric. Sci, 24, 1012-1019.

24. Nasir, M., Al-Kutti, W., Kayed, T.S., Adesina, A., and Chernykh, T. 2021. Synthesis and SWOT analysis of date palm frond ash-Portland cement composites. Environmental Science and Pollution Research, 1-13.

25. Novak, J. M., Lima, I., Xing, B., Gaskin, J. W., Steiner, C., Das, K. C.,... and Schomberg, H. 2009. Characterization of designer biochar produced at different temperatures and their effects on a loamy sand. Annals of Environmental Science, 3(1), 195-206.

26. Okeola, F.O., and Odebunmi, E.O. 2010. Comparison of Freundlich and Langmuir isotherms for adsorption of methylene blue by agrowaste derived activated carbon. Advances in Environmental Biology, 4(3), 329-335.

27. Palágyi, S., Salzer, P., and Mitro, A. 2006. Sorption, desorption and extraction of cadmium from some arable and forest soils. Journal of Radioanalytical and Nuclear Chemistry, 269(1), 103-113.

28. Rao, C.R.M., Sahuquillo, A., and Lopez Sanchez, J.F. 2008. A review of the different methods applied in environmental geochemistry for single and sequential extraction of trace elements in soils and related materials. Water Air Soil Pollut, 189, 291-333.

29. Singh, E., Kumar, A., Mishra, R., You, S., Singh, L., Kumar, S., and Kumar, R. 2021. Pyrolysis of waste biomass and plastics for production of biochar and its use for removal of heavy metals from aqueous solution. Bioresource Technology, 320, 124278.

30. Sutcu, M., Erdogmus, E., Gencel, O., Gholampour, A., Atan, E., and Ozbakkaloglu, T. 2019. Recycling of bottom ash and fly ash wastes in ecofriendly clay brick production. Journal of Cleaner Production, 233, 753-764.

31. Trakal, L., Bingöl, D., Pohořelý, M., Hruška, M., and Komárek, M. 2014. Geochemical and spectroscopic investigations of $\mathrm{Cd}$ and $\mathrm{Pb}$ sorption mechanisms on contrasting biochars: engineering implications. Bioresource technology, 171, 442-451.

32. Ugulu, I., Khan, Z. I., Aslam, Z., Ahmad, K., Bashir, H., and Munir, M. 2021. Potentially toxic metal accumulation in grains of wheat variety Galaxy-2013 irrigated with sugar industry wastewater and human health risk assessment. Euro-Mediterranean Journal for Environmental Integration, 6(1), 1-11.

33. Ungureanu, O. I., Bulgariu, D., Mocanu, A. M., and Bulgariu, L. 2020. Functionalized PET waste based low-cost adsorbents for adsorptive removal of $\mathrm{Cu}$ (II) ions from aqueous media. Water, 12(9), 2624.

34. Usman, A. R., Abduljabbar, A., Vithanage, M., Ok, Y. S., Ahmad, M., Ahmad, M.,... and Al-Wabel, M. I. 2015. Biochar production from date palm waste: charring temperature induced changes in composition and surface chemistry. Journal of Analytical and Applied Pyrolysis, 115, 392-400.

35. Usman, A., Sallam, A., Zhang, M., Vithanage, M., Ahmad, M., Al-Farraj, A., Ok, Y.S., Abduljabbar, A. and Al-Wabel, M. 2016. Sorption process of date palm biochar for aqueous Cd (II) removal: Efficiency and mechanisms. Water, Air, \& Soil Pollution, 227(12), 1-16.

36. Zhao, Y., Qamar, S. A., Qamar, M., Bilal, M., and Iqbal, H. M. 2021. Sustainable remediation of hazardous environmental pollutants using biocharbased nanohybrid materials. Journal of Environmental Management, 300, 113762.

37. Zheng, Y., Hua, S., and Wang, A. 2010. Adsorption behavior of $\mathrm{Cu}^{2+}$ from aqueous solutions onto starch-g-poly (acrylic acid)/sodium humate hydrogels. Desalination, 263, 170-175. 